\title{
Sumário do Curriculum de Florestan Fernandes*
}

ASCIDO EM 22 de julho de 1920 na cidade de São Paulo; casado com
$\begin{aligned} & \text { Myrian Rodrigues Fernandes; cinco filhas e um filho; oito netas, qua- } \\ & \text { tro netos, um bisneto e uma bisneta. }\end{aligned}$

Faleceu em 10 de agosto de 1995, seis dias após ter sido submetido a uma operação de transplante de fígado no Hospital das Clínicas da Faculdade de Medicina da Universidade de São Paulo.

\section{Aprendizagem}

- Curso primário incompleto (até terceiro ano): Grupo Escolar Maria José, Bela Vista, São Paulo.

- Cursos secundário e colegial (Curso de Madureza), sob o artigo 100: Ginásio Riachuelo (anos letivos de 1938, 1939 e 1940).

- Curso superior: Ciências Sociais, na Faculdade de Filosofia, Ciências e Letras da Universidade de São Paulo (anos letivos de 1941, 1942 e 1943). Licenciatura no curso de Didática da Faculdade de Filosofia, Ciências e Letras da USP no letivo de 1944).

- Curso de pós-graduação em Sociologia e Antropologia: Escola Livre de Sociologia e Política, São Paulo (anos letivos de 1945 e 1946).

Títulos acadêmicos

- Mestre em Ciências Sociais (Antropologia): Escola Livre de Sociologia e Política (1947), com a tese $A$ organização social dos Tupinambá.

- Doutor em Ciências Sociais (Sociologia): Faculdade de Filosofia, Ciências e Letras da USP (1951), com a tese $A$ função social da guerra na sociedade Tupinambá.

- Livre-docente: Cadeira de Sociologia I, Faculdade de Filosofia, Ciências e Letras da USP (1953), com a tese Ensaio sobre o método de interpretação funcionalista na Sociologia.

- Professor titular: Cadeira de Sociologia I, Faculdade de Filosofia, Ciências e Letras da USP (1964), com a tese $A$ integração no negro na sociedade de classes. 


\section{Cargos ocupados}

- Segundo-assistente da cadeira de Sociologia II da Faculdade de Filosofia, Ciências e Letras da USP (1/3/1945 a 27/11/1952).

- Primeiro-assistente da cadeira de Sociologia I da Faculdade de Filosofia, Ciências e Letras da USP $(27 / 11 / 1952$ a 31/12/1954).

- Professor contratado da cadeira de Sociologia I da Faculdade de Filosofia, Ciências e Letras da USP (1/1/1954) a 23/2/1965).

- Professor catedrático efetivado por concurso de títulos e provas, a partir de 23/2/1965. Afastado sob aposentadoria compulsória, com vencimentos proporcionais ao tempo de serviço, em 24/4/1969, por aplicação do Ato Institucional $\mathrm{n}^{\mathbf{0}} \mathbf{5}$ pela ditadura militar.

- Vários: Visiting-scholar na Columbia University (último semestre de 1965 a janeiro de 1966); professor de Sociologia, como Latin American in Residence, na Universidade de Toronto (1969/1970). Professor titular na Universidade de Toronto a partir de 1970; resignou, em fins de 1972, para regressar ao Brasil. Professor de cursos de extensão cultural no Instituto Sedes Sapientiae (1976 e 1977); professor contratado da Pontifícia Universidade Católica de São Paulo, último trimestre de 1977. Visiting-professor na Yale University, primeiro semestre de 1977. Professor titular da Pontifícia Universidade Católica de São Paulo, 1978.

\section{Atividade parlamentar}

- Deputado Federal Constituinte pelo Partido dos Trabalhadores (PT) no período de 1987 a 1990.

- Deputado Federal pelo Partido dos Trabalhadores (PT), reeleito para o período de 1991 a 1994.

\section{Trabalhos publicados $\left.{ }^{*}\right)$}

- Karl Marx, Contribuição à crítica da economia política, tradução e introdução. São Paulo, Flama, 1946.

- A organização social dos Tupinambá, São Paulo, Instituto Progresso Editorial, 1949; 2a. ed., São Paulo, Difusão Européia do Livro, 1963.

(*) Com exceção de livros de múltipla autoria e de colaboração em jornais e revistas. Tal colaboração foi iniciada em 1943, chegando a ter continuidade, por longo tempo, em $O$ Estado de $S$. Paulo, Folha da Manhã, Folha de S. Paulo, desde 27/10/80 e Jornal do Brasil, desde 25/9/ 87, Jornal de Brasília, desde 25/9/88. 
- A função social da guerra na sociedade tuipinambá, São Paulo, Museu Paulista, 1952; 2a. ed., São Paulo, Pioneira/Edusp, 1970.

- A etnologia e a sociedade no Brasil. Ensaio sobre aspectos da formação e desenvolvimento das Ciências no Brasil, São Paulo, Anhembi, 1958.

- Negros e brancos em São Paulo, em colaboração com Roger Bastide, Ed. Independente, São Paulo, Companhia Editora Nacional, 1959; 3a. ed., 1971. Publicação prévia, Revista Anbembi, 1953; ed. original, com outros trabalhos de vários autores, São Paulo, Editora Anhembi, 1955.

- Mudanças sociais no Brasil, São Paulo, Difusão Européia do Livro, 1960; 2a. ed., refundida, com um ensaio global introdutório, 1974, 3a. ed., 1979.

- Ensaios de sociologia geral e aplicada, São Paulo, Pioneira, 1960; 2a. ed., 1971; 3a. ed., 1976.

- Folclore e mudança social na cidade de São Paulo, São Paulo, Anhembi, 1961; 2a. ed., Petrópolis, Vozes, 1979.

- A sociologia numa era de repolução social, São Paulo, Companhia Editora Nacional, 1962; 2a. ed. reorganizada e ampliada, Rio de Janeiro, Zahar, 1976.

- A integração do negro na sociedade de classes, São Paulo, Faculdade de Filosofia, Ciências e Letras da USP, 1964; 2a. ed., em dois volumes, São Paulo, Dominus/Edusp 1965; 3a. ed., em dois volumes, Ática, 1978.

- Educafãa e sociedade no Brasil, São Paulo, Dominus/Edusp, 1966.

- Fundamentos empíricos da explicação sociológica, São Paulo, Companhia Editora Nacional, 1967; 2a. ed., 1967, reimpressão, 1972; 3a. ed., Rio de Janeiro, Livros Técnicos e Científicos, 1978; 4a. ed., T.A. Queiroz, Editor, 1980.

- Sociedade de classes e subdesenvolvimento, Rio de Janeiro, Zahar, 1968; 2a. ed., 1972, 3a. ed., 1975, 4a. ed., 1981.

- The Latin American in residence lectures, Toronto, University of Toronto, $1969 / 1970$.

- Elementos de sociologia teórica, São Paulo, Companhia Editora Nacional, 1970; 2a. ed., 1974.

- O negro no mundo dos brancos, São Paulo, Difusão Européia do Livro, 1972. 
- Comunidade e sociedade no Brasil (como organizador). Leituras básicas de introdução ao estudo macro-sociológico do Brasil, São Paulo, Companhia Editora Nacional, 1972; 2a. ed., 1975.

- Comunidade e sociedade (como organizador). Leituras sobre problemas conceituais, metodológicos e de aplicação. São Paulo, Companhia Editora Nacional, 1973.

- Comunidade e sociedade (como organizador), tomos ainda inéditos.

- Las classes sociales en América Latina (em co-autoria com N. Poulantzas e A. Touraine) México, Siglo Veintiuno Editores, Unam, 1973; publicado no Brasil como As classes sociais na América Latina, Rio de Janeiro, Paz e Terra, 1977.

- Capitalismo dependente e classes sociais na América Latina, Rio de Janeiro, Zahar, 1973; 2a. ed., 1975: 3a. ed., 1981.

- A investigação etnológica no Brasil e outros ensaios, Petrópolis, Vozes, 1975.

- A repolução burguesa no Brasil. Ensaio de interpretação sociológica, Rio de Janeiro, Zahar, 1975; 2a. ed., 1976; 3a. ed., 1981.

- A universidade brasileira: reforma ou revolução?, São Paulo, Alfa-Ômega, 1975 ; 2a. ed., 1979.

- Circuito fechado. Quatro ensaios sobre o "Poder Institucional”, São Paulo, Hucitec, 1976; 2a. ed., 1977.

- A sociologia no Brasil. Contribuifão para o estudo de sua formação e desenvolvimento, Petrópolis, Vozes, 1977; 2a. ed., 1980.

- A condição de sociólogo, São Paulo, Hucitec, 1978.

- O folclore em questão, São Paulo, Hucitec, 1978.

- Lênin, organização e introdução (p. 7-49), São Paulo, Ática, 1978 (duas edições).

- Da guerrilha ao socialismo: a revolução cubana, São Paulo, T.A. Queiroz Editor, 1979.

- Apontamentos sobre a "Teoria do Autoritarismo", São Paulo, Hucitec, 1979.

- Brasil: em compasso de espera, São Paulo, Hucitec, 1980. 
- A natureza sociológica da sociologia, São Paulo, Ática, 1980.

- Movimento socialista e partidos políticos, São Paulo, Hucitec, 1980.

- Poder e contra-poder na América Latina, Rio de Janeiro, Zahar, 1981.

- O que é revolução?, São Paulo, Brasiliense, 1981 (seis edições).

- A ditadura em questão, São Paulo, T.A. Queiroz Editor, 1982 (duas edições).

- K. Marx - F. Engels: histbria, organização e introdução (p. 9-143), São Paulo, Ática, 1983.

- A questão da USP, São Paulo, Editora Brasiliense , 1984.

- Que tipo de república?, São Paulo, Brasiliense, 1986 (três edições).

- Nova República?, Rio de Janeiro, Zahar, 1986 (três edições).

- Oprocesso constituinte, Brasília, Câmara dos Deputados, Centro de Documentação e Informação, 1988.

- A Constituição inacabada, vias históricas e significado, São Paulo, Estação Liberdade Editora, 1989.

- O desafio educacional, São Paulo, Cortez, 1989.

- Pensamento e ação: o PT e os rumos do socialismo, São Paulo, Brasiliense, 1989.

- O significado do protesto negro, São Paulo, Cortez, 1989.

- A transifão prolongada, São Paulo, Cortez, 1990.

- As lições da eleição, Brasília, Câmara dos Deputados, Centro de Documentação e Informação, 1990.

- Depoimento, in memória viva da educafão brasileira, 1, Brasília, Inep, 1991.

- O PT em movimento - contribuição ao I Congresso do Partido dos Trabalhadores, São Paulo, Cortez/Autores Associados, 1991.

- Reflexão sobre o socialismo e a autoemancipação dos trabalbadores, São Bernardo do Campo, Departamento de Formação Política e Sindical, Sindicato dos Metalúrgicos de São Bernardo e Diadema, 1992:

- Parlamentarismo: contexto e perspectivas, Brasília, Câmara dos Deputados, Centro de Documentação e Informação, 1992. 
- LDB: impasses e contradições, Brasília, Câmara dos Deputados, Centro de Documentação e Informação, 1993.

- Democracia e desenvolvimento - a transformação da periferia e o capitalismo monopolista da era atual, São Paulo, Hucitec, 1994.

- Consciência negra e transformação da realidade, Brasília, Câmara dos Deputados, Centro de Documentação e Informação, 1994.

- Tensões na educação, Salvador, Sarah Letras, 1995.

- A contestafãa necessária, São Paulo, Ática, 1995.

- Em busca do socialismo, São Paulo, Xamã, 1995.

- Brasil 1986/1994: atraso e modernidade, Salvador, Sarah Letras (em organização).

- O pensamento político de Marighella, in Anais do Seminário sobre Carlos Marigbella, Salvador, UFBa, (em organização).

Trabalhos publicados

em outras línguas, como tradução

- La guerre et le sacrifice humain chez les Tupinambá, tradução de Suzanne Lussagnet, publicado e editado em separata por Journal de La Societé des Americanistes, Paris, Musée de L'Homme, 1952.

- Fundamentos empiricos da explicação sociológica, México, Unam, sd (em espanhol).

- The negro in Brazilian society, Tradução de Jacqueline D. Skiles, A. Brunel e Arthur Rothwell, editado por Phyllis B. Eveleth, New York/Londres, Columbia University Press, 1969 e, como paperback, New York, Atheneum, 1971.

- Die integration des Negers in die Klassengesellschaft, v. 1, Verlag Gehlen, Bad Homburg v.d.H, Berlin/Zurich, 1969 (tradução de Dr. Jrgen Grabvener); v. 2, Wilhelm Fink Verlag, Munchen, 1977 (tradução de Angela Dulle).

- La revolución burguesa en Brasil, tradução de Eduardo Molina, México, Siglo Veintiuno Editores, 1978.

- Reflections on the Brazilian counter-repolution, organizado com introdução de Warren Dean, Armonk, New York, M. E. Sharpe, Inc., 1981. 


\section{Obras a seu respeito}

- Barbara Freitag, Die Sozio-Okonomische Entwiklung Brasiliens ans der Sicht Eines Brasilianischen Sozialwissenshaftlers, Saabruchen 1969, Verlag der SSIP-Schriften D. Breitenbach, Saarbrucken Universitat.

- Octávio Ianni (organizador), Florestan Fernandes, São Paulo, Editora Ática, 1986.

- Maria Angela D'Incao (organizadora), O saber militante. Ensaios sobre Florestan Fernandes, São Paulo, Unesp/Paz e Terra, 1987.

- Gabriel Colins, Padrões e dilemas: o pensamento de Florestan Fernandes, in R. Moraes, R. Antunes e V. B. Ferrante (orgs..), Inteligência brasileira, São Paulo, Brasiliense, 1989, p. 125-148.

Distinções e Prêmios

- Prêmio Temas Brasileiros, Grêmio da Faculdade de Filosofia, Ciências e Letras da USP, 1944 (com o trabalho As Trocinbas do Bom Retiro. Selecionador e Julgador: Professor Roger Bastide).

- Prêmio Fábio Prado, 1948.

- Medalha Silvio Romero, Prefeitura do Rio de Janeiro, DF, 1958.

- Título de Cidadão Emérito, conferido pela Câmara Municipal de São Paulo, (24/4/1961).

- Prêmio Jabuti de Ciências Sociais, 1963.

- Prêmio Sociedade Brasil-Israel, São Paulo, 1966.

- Prêmio The Anisfield-Wolf Award in Race Relations for 1969 (Cleveland Foundation sponsored by the Saturday Review) Comitê selecionador e julgador em 1969: Ashley Montagu, chairman, Oscar Handlin e Pearl Buck).

- Professor Emérito, Universidade de São Paulo, 1985.

- Doutor Honoris Causa, Universidade de Utrecht, 1986.

- Prêmio Estácio de Sá, categoria Ciência, Governo do Estado do Rio de Janeiro, 1989.

- Doutor Honoris Causa, Universidade de Coimbra, 1990.

- Ordem Nacional do Mérito Educatipo, grau de Grande Oficial, Ministério da Educação, 1993. 


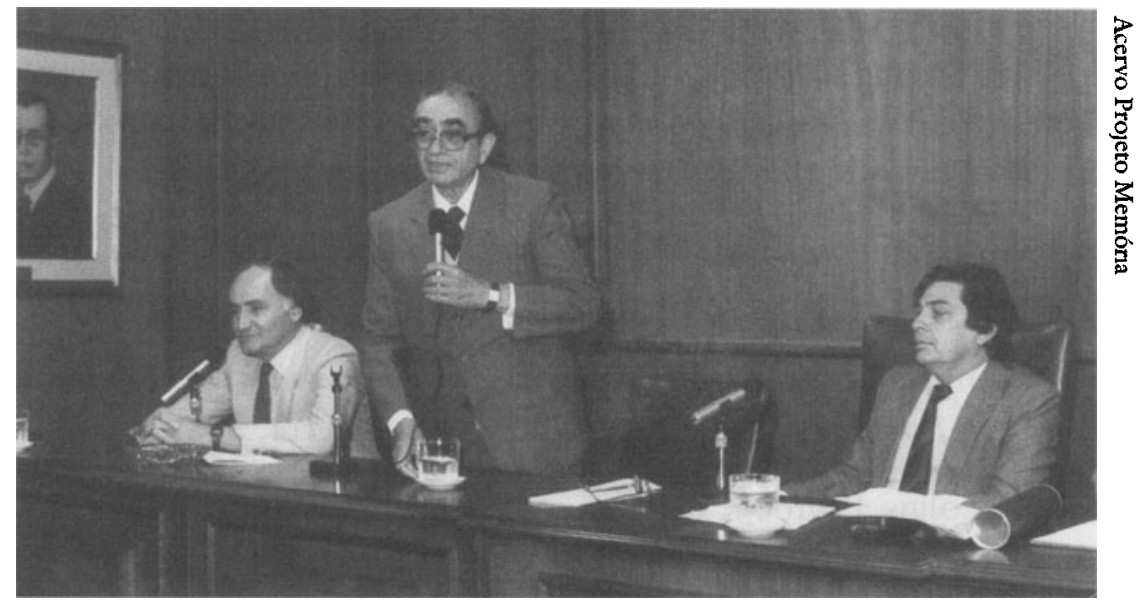

Em 1985, Florestan receben o titulo de professor emérito da USP

- Prêmio Almirante Álvaro Alberto/Ciências Humanas, Secretaria de Ciência e Tecnologia da Presidência da República/CNpq, 1993.

- Cidadão Honorário de São Carlos, Câmara Municipal de São Carlos, 1994.

- Ordem de Rio Branco, grau de Grande Oficial, Ministério das Relações Exteriores, 1995.

- Cidadão Honorário de Brasilia, Câmara Legislativa do Distrito Federal (homenagem póstuma), 1995.

* Levantamento realizado por Vladimir Sacchetta e atualizado em dezembro de 1995. 